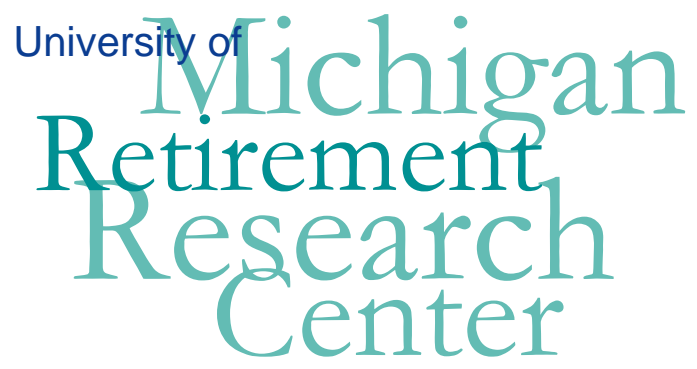

Working Paper WP 2007-168

Estimating the Health Effects of Retirement John Bound and Timothy Waidmann

\begin{tabular}{|c|c|}
\hline $\mathrm{M}$ & $\mathrm{R}$ \\
\hline $\mathrm{R}$ & $\mathrm{C}$ \\
\hline
\end{tabular}$\quad$ Project \#: UM07-08 


\title{
Estimating the Health Effects of Retirements
}

\author{
John Bound \\ University of Michigan \\ Timothy Waidmann \\ The Urban Institute
}

October 2007

\author{
Michigan Retirement Research Center \\ University of Michigan \\ P.O. Box 1248 \\ Ann Arbor, MI 48104 \\ http://www.mrrc.isr.umich.edu/
}

(734) 615-0422

\section{Acknowledgements}

This work was supported by a grant from the Social Security Administration through the Michigan Retirement Research Center (Grant \# 10-P-98362-5-04). The findings and conclusions expressed are solely those of the author and do not represent the views of the Social Security Administration, any agency of the Federal government, or the Michigan Retirement Research Center.

\section{Regents of the University of Michigan}

Julia Donovan Darrow, Ann Arbor; Laurence B. Deitch, Bingham Farms; Olivia P. Maynard, Goodrich; Rebecca McGowan, Ann Arbor; Andrea Fischer Newman, Ann Arbor; Andrew C. Richner, Grosse Pointe Park; S. Martin Taylor, Gross Pointe Farms; Katherine E. White, Ann Arbor; Mary Sue Coleman, ex officio 


\title{
Estimating the Health Effects of Retirement
}

\author{
John Bound and Timothy Waidmann
}

\begin{abstract}
We estimate the magnitude of any direct effect of retirement on health. Since retirement is endogenous to heath, it is not possible to estimate this effect by comparing the health of individuals before and after they retire. As an alternative we use institutional features of the pension system in the United Kingdom that are exogenous to the individual to isolate exogenous variation in retirement behavior. Data used will include both vital statistics and survey data that include both "objective" physical measurements and respondent self-reports. We find no evidence of negative health effects of retirement and some evidence that there may be a positive effect, at least for men.
\end{abstract}

\section{Authors’ Acknowledgements}

The research reported herein was pursuant to a grant from the U.S. Social Security Administration (SSA) funded as part of the Retirement Research Consortium (RRC). The findings and conclusions expressed are solely those of the authors and do not represent the views of SSA, any agency of the Federal Government or the RRC. The authors wish to thank Saad Ahmad for research assistance and Joanna Lahey for her useful comments on an earlier version of this report. 


\section{Introduction}

As the large birth cohorts of the baby boom approach eligibility age for social security old-age benefits, concerns for the fiscal stability of the program have prompted proposed policies to encourage aging workers to postpone retirement. If successful, they would both increase revenues into the system and decrease benefit payments. Beyond fiscal implications, however, delayed retirement may lead to other outcomes that make the social welfare impact ambiguous. One outcome that has not been well-studied is the potential health impact of delayed retirement, and one can imagine retirement being either a positive or negative influence on health. For example, for an individual in a physically demanding job that constitutes an ongoing stressor to health, retiring could be good for health, and postponing retirement could impose an added burden on individuals as well as potentially increased costs for private and public financing of health care.

Alternatively, one could imagine scenarios in which retirement leads to the worsening of a person's health. For example, mental activity has been associated with reduced risk of dementia, and the physical activity of work may serve to reduce risks of obesity and diabetes.

Measuring the effect of retirement on health would also inform research on the determinants of retirement. Most models of retirement (e.g., Bound Stinebrickner and Waidmann 2004) treat health as an exogenous to the retirement decision. It is understood that over the life course health is endogenous to both private and public investments in health. That said, it seems plausible that much of the variation in health and changes in health that occur when men and women are approaching retirement age can be considered exogenous to retirement behavior. If retirement were to have a direct effect on health, then estimates of typical retirement models would be systematically biased. 
Other researchers who have examined the effect of health on retirement have typically compared the health of individuals before and after they retire (e.g. Dave, Rashad and Spasojevic, 2006). Researchers following this kind of strategy have often found that retirement has large negative effects on both physical and mental health. However, if deteriorating health leads individuals to retire, this approach will tend to seriously exaggerate the negative effects of retirement on health.

We estimate the magnitude of any direct effect of retirement on health using a procedure similar to that used by Charles, (2002) to determine if exogenous variation in retirement is associated with variation in several indicators of health. The idea is to compare health indicators immediately before normal retirement age. In the United Kingdom, a significant portion of retirement income for large numbers of individuals is available at age 65 for men and 60 for women. This feature provides a strong incentive for retirement at those ages, and data on labor force attachment show drops at those ages. On the other hand, there is nothing unique about those ages that influences health. By contrast, in the U.S. there are two rather than one spike in retirements and retirement effects health insurance status.

The approach we are using here bears a resemblance to a regression discontinuity (RD) design. However, we want to note that there are important distinctions between our approach and the regression discontinuity approach. In the context a RD design one is looking for a distinct jump at the point of discontinuity. In our case, we do not expect to see such a jump, but do expect that if, for example, retirement tends to have a distinct positive effect on health, we should see health above trend in the years following the age of normal retirement. 


\section{The Possible Health Effects of Retirement}

There are a number of reasons we might imagine that retirement, per se, might affect health. Individuals retire for a number of different reasons. In what follows we will focus on the case in which the net value (both pecuniary and non pecuniary) of continuing to work declines to the point that a person retires. We are imagining the case where this decline is fully anticipated. Canonical examples of this would include the case in which an individual is induced to retire at a certain age by the incentives built into either public or private pension systems.

Grossman (1972) models health as a form of human capital. Changes in health depend, in part, on investments in health, with these investments being functions of both time and medical care. After retirement, non-market time increases. As a result, we would expect the time individuals spend investing in their health would rise, with this being especially true if such investments are time intensive. Here, what we have in mind includes both time spent pursing medical care and time spent in health promoting behaviors. At the same time, the extra time could also be spent in engaged in unhealthy behaviors.

The notion that working, per se, might have negative effects on health that work through patterns of time use is consistent with recent work that has consistently found that recessions tend to be associated with decreases in mortality and improvements in physical health. Available evidence suggests that these changes are, in part, due to life style and health behavior changes that occur during recessions (see Ruhm 2004 for a summary and discussion of the research relating macro economic conditions and health).

In Grossman's model, health increases the value of time spent in both market and 
non market activities. If the marginal value of health is greater in one of these activities than the other, this gap could affect investment behavior as someone neared retirement age. Whatever their strength early in working life, we suspect that the private incentives to take care of one's health in order to augment market productivity to be weak as one approaches retirement. While worker productivity does tend to drop as workers age, older workers have typically found themselves in jobs that do not pay piece rates. Our sense is that much of the burden of declining productivity among older workers is born by employers, not workers. To the extent that this is the case, retirement means moving from a situation where the individual captures a small share of the benefits of taking care of him/herself to a situation where he/she gets to enjoy all of the benefits. As a result, one would expect investments in health to increase as an individual nears retirement. This said, these behavioral changes should occur prior to retirement.

There are other reasons we might expect that retirement could possibly affect health. On the one hand jobs that are stressful or physically demanding could have a negative effect on health. On the other hand, work and related activities may be one of the primary forms of physical activity for some individuals. In addition, social networks formed at work may be important for many, and the strength of these networks may weaken with retirement. Lastly, work, itself, may be rewarding. In all such cases, continued employment would tend to have a positive effect on a persons mental or physical health.

Clearly, it would seem theoretically possible that retirement could have either positive or negative effects on health. Indeed, it seems natural to imagine that both the direction and magnitude of these effects would vary across individuals. At best we will 
be able to estimate and average effect. The magnitude of the effect of retirement on health will also depend on the relative importance of contemporaneous investments versus other factors in determining current health. To illustrate this point, imagine that health in period $t$ depends on health in period $t-1$, health investments in period $t-1$ and idiosyncratic shocks: $\mathrm{H}_{\mathrm{t}+1}=\gamma \mathrm{H}_{\mathrm{t}}+\delta \mathrm{I}_{\mathrm{t}}+v_{\mathrm{t}}$. The impact of investments ( $\left.\mathrm{I}_{\mathrm{t}}\right)$ on future health depends on the productivity of these investments (the magnitude of $\delta$ ), the persistence of health over time (the magnitude of $\gamma$ ) and on the typical magnitude of health shocks (the variance of $v_{t}$ ).

\section{Retirement in the United Kingdom}

Normal retirement age in the United Kingdom is 65 for men and 60 for women. This is the age at which men and women can begin to receive state retirement benefits. As a result, a large fraction, at least of men, have traditionally left the labor force at this age. Thus, for example, Blundell and Johnson (1999) using the U.K. family expenditure survey calculate a roughly 50 percentage point drop in labor force participation rates at age 65 for men born in 1913 and reaching retirement age in 1978. However, as is true in many other developed countries, the participation rates of men near retirement have dropped dramatically over the last 30 years. ${ }^{1}$ In recent cohorts the drop in labor force participation rates for men at 65 is closer to 20 percentage points.

The pension system in the U.K includes important public and private components. The basic state pension provides benefits at flat rate for men and women who have reached normal retirement age so long as they have contributed sufficiently to the national insurance system. In addition, the State Earnings Related Pension Scheme

\footnotetext{
${ }^{1}$ Employment rates for $60-64$ year old men dropped from $80 \%$ in the 1968 to $40 \%$ in the late 1990 s (Blundell, Meghir and Smith, 2002).
} 
(SERPS) provides a pension equal to $20 \%$ of an individual's qualifying annual earnings. In addition means tested Income Support is a flat rate system available for the elderly. Unlike younger individuals, those over the age of 60 do not need to be looking for work to receive benefits. Lastly, Invalidity Benefits are available for those who can pass a medical screen.

In addition to the publicly provided pension benefits, many individuals in the U.K. are eligible for private pension benefits. Close to half of workers are covered by an occupational pension. In addition, many workers in the U.K, have individual retirement accounts. Since 1988 individuals have been allowed to contract out of SERPS to take out an individual retirement account. Blundell, Meghir and Smith argue that the drop in the labor force participation of men in their $60 \mathrm{~s}$ can be largely attributed to the growth of private pensions.

\section{Data and Methods}

In this study we examine several types of health measures for shifts after normal retirement ages. Data for these analyses come from two sources. For the analyses of morbidity, we use the second wave of the English Longitudinal Study of Aging (ELSA). The ELSA, begun in 2002, interviewed approximately 12,000 individuals and is drawn to represent the resident population of England ages 50 and older. It was modeled after the Health and Retirement Study and contains detailed information on demographics, economic resources, labor force activity and health. The second wave was fielded in 2004, and as part of the "nurse visit" component of the survey it included several physical performance measurements and a series of tests performed on a blood sample taken at the interview. 
We focus on two types of variables, self-reported measures of health and functional status, and "objective" physical measurements. The self-reported measures include measures of limitation in physical function (Nagi items), difficulty with activities of daily living (ADLs) and instrumental activities of daily living (IADLs), general health status (fair or poor health), the presence of a longstanding illness that limits activities, and being frequently bothered by pain.

The objective measures we use include a subset of the items found in the Short Physical Performance Battery (Guralnik et al. 1994). Specifically, for all members of the sample, the nurse asks respondents to stand from a sitting position without using their arms and then asks them to repeat this 5 times, while being timed. To measure balance, the nurse directs respondents to stand in three separate positions (feet together side by side, slightly offset, and in the full tandem position, i.e., heel to toe) for about 10 seconds. Older sample members (60 and above) are also timed as they walk a distance of 4 meters. Guralnik and colleagues constructed a scale based on all of these items, but because the sample receiving the entire battery of tests excludes much of the pre-retirement age sample, we base a scale only on the balance and standing portions of the test. The scoring for these items allows a maximum score of 9 points. Approximately one quarter of the sample has a score lower than 7 , which we take as a threshold value for some of our analyses.

The second set of objective measures are based on blood chemistry and anthropometric tests. Among the measures collected by ELSA are those sufficient to diagnose "metabolic syndrome," a set of symptoms linked to overweight and obesity that are risk factors for coronary heart disease. The presence of three out of the five 
symptoms (excessive waist circumference, elevated triglyceride level, low levels of HDL cholesterol, high blood pressure, and elevated fasting blood glucose) is classified as metabolic syndrome (National Heart Lung and Blood Institute, 2007). We use both the dichotomous indicator for having 3 of the 5 symptoms as well as the total number of symptoms as dependent variables in our analyses.

For the analysis of causes of mortality we use data from the UK vital statistics system. Specifically, from the UK Office for National Statistics, we obtained data on numbers of deaths by cause (ICD10), sex, and single year of age in England and Wales during the calendar year 2005. These were compiled from death registration records. Population estimates for England and Wales at mid-year of 2005, by age and sex were downloaded from the website of the Office for National Statistics (www.statistics.gov.uk). Using standard demographic methods, we calculate causespecific life-table death rates by age and sex for several broad groups of conditions that capture more than $90 \%$ of deaths in the older population: diseases of the circulatory system (38\%), neoplasms (29\%), diseases of the respiratory system (15\%), diseases of the digestive system (4\%), diseases of the nervous system (3\%), as well as "external" causes, that in this population are predominantly accidents (2\%). For this analysis we limit our attention to mortality between the ages of 30 and 90 .

As our principal mode of analysis to estimate the effect of retirement on health, we estimate the effect of public pension eligibility (being age 60 and above for women, or age 65 and above for men) on the morbidity and mortality measures to see if there are discernible deviations in the age pattern of health measures at pension eligibility ages.

For the dichotomous variables, we use a logit specification, and for the scale 
variables (physical performance and the number of metabolic syndrome symptoms present) we use an ordered logit specification. We use several specifications for age variables to examine the potential effect of retirement eligibility on health. We looked for shifts that occur after retirement both in the levels of health and in the age-trends in health.

For mortality rates, we estimate linear regression models on the logged mortality rates for the various disease groups using the same strategy of observing deviations from trends established before retirement age.

\section{Results}

Morbidity: Results for measures obtained from the ELSA are shown in Figures 1 through 18. In these figures, we first plot logit coefficients from age dummy variables for each measure from age 53 through 89 , and then plot the age trend in these coefficients as estimated from pre-retirement ages. We then display results from the statistical test that the coefficients from the post-retirement ages deviate from the pre-retirement trend. To examine whether deviations are "temporary," i.e., concentrated around retirement, we also test the hypothesis that the first 10 years after retirement age deviate from the preretirement trend.

Considering first the objective measures, men appear to have a slight improvement in health relative to trend after 65 as measured by the probability of scoring below 7 on the abbreviated performance battery (Figure 1) and by the probability of exhibiting three of the five indicators of metabolic syndrome (Figure 2). For the performance battery, however, this improvement appears to be temporary. While the first ten years past retirement are significantly different from trend, when we consider all ages 
up to 90 , there is no longer a statistically significant deviation. Looking at coefficients from the ordered logit model of the battery score (Figure 3) we see no significant deviation from the downward trend in the score. Similarly, the coefficients from the model of the count of heart disease risk factors shown in Figure 4 do not deviate significantly from trend.

The age patterns in many of the self-reported measures for men shown in Figures 5 through 9 show a consistent improvement relative to pre-retirement trend. The measure most closely related to the performance battery is reported difficulty with a lower-body functioning item (these include standing, sitting for long periods, stooping or kneeling, or climbing stairs). This measure (Figure 5) shows a statistically significant pattern of better functioning than would be predicted by pre-retirement trends. Although the effects appear smaller than for other self-reported measures, they do persist unlike the trends in Figure 1. Most closely related to the metabolic syndrome indicators is having a doctor's diagnosis of a condition related to heart disease (heart attack, angina, or high blood pressure) or diabetes. In the coefficients for this measure (Figure 6), there is no significant deviation from the pre-retirement trend.

Figures 7,8 and 9 show that for men, reporting a chronic illness that limits activities, rating one's health as fair or poor, and reporting frequent trouble with pain all show statistically significant improvements relative to trend after the normal retirement age. We find the same results for measures of difficulty with upper body function, ADLs, and IADLs.

Among women, age trends in the objective measures of health and function show 
some similarities to those of men, though they are generally not as strong, statistically. ${ }^{2}$ In the probability of scoring below 7 on the performance battery (Figure 10), there is a statistically insignificant improvement relative to trend, and in the probability of having at least three risk factors for heart disease (Figure 11), a statistically insignificant improvement, but not until after age 70. From the ordered logit models (Figures 12 and 13), there is a statistically significant decline relative to trend in the performance battery score, but it does not appear until after age 70, and no significant deviation in the number of metabolic syndrome symptoms. Overall, the patterns in objective measures for women do not suggest a retirement effect on health.

Comparing these findings to those for the self-reported analogs for lower body functioning and heart disease in Figure 14, we find a significant improvement relative to trend in lower body function, in the first 10 years that persists throughout the postretirement period. In self-reported heart disease/diabetes (Figure 15), there is a significantly higher rate of these reports relative to trend after age 60. As with men, we find patterns consistent with a retirement age improvements in the subjective reports of a chronic disease causing activity limitations, fair or poor health, and frequent problems with pain, shown in Figures 16, 17 and 18.

Mortality: Age patterns of mortality rates do not consistently conform to a model of retirement-induced changes in health. Rather, it seems more likely that basic biological factors are at work. Certain causes of death tend to accelerate with age while others tend to decelerate. It is likely that other factors are driving these trends. Plots (19 \& 20) for all internal causes of death (those related to organ systems) in aggregate show no deviation

\footnotetext{
${ }^{2}$ Because the pre-retirement period observable in the wave 2 data is only 7 years, the pre-retirement trends are estimated with less precision, reducing the statistical power of the tests on deviation from trend.
} 
from trend through age 90 for men or women. For both men and women, cancer deaths tend to decline relative to trend (Figures $21 \& 22$ ) while nervous system mortality tends to increase relative to trend (Figures $23 \& 24$ ). It is difficult to believe that retirement is driving these causes in opposite directions. Death rates due to circulatory system diseases, the most common cause of death after 50, show strikingly different patterns for men and women (Figures $25 \& 26$ ). Women's circulatory mortality rates accelerate somewhat in old age while men's rates decelerate. The shift in women's rates may be due to the protective effect of endogenous estrogen against coronary artery disease before menopause (Lawlor et al. 2002). External cause mortality (Figures $27 \& 28$ ) appears to increase after retirement, yet it is difficult to plausibly describe this change as a health effect of retirement.

\section{Conclusion}

Our tabulations have suggested that, if anything, at least for men, retirement would seem to have a small positive effect on physical health. This evidence mirrors the Charles finding for psychological well-being, but contrasts markedly with Dhaval, Rashad, and Spasojevic findings. This contrast mirrors the difference in the methodology between the various researchers. Dhaval, Rashad, and Spasojevic use longitudinal data to follow individuals over time. They find that retirement between period $t-1$ and $t$ is associated with declines in various health measures over the same interval. It seems at least as plausible that the correlation they have uncovered represents the effect of changing health on behavior as much as it does the effect of retirement on health. In contrast, Charles and the two of us follow a strategy of trying to find exogenous factors affecting retirement. 
Just as there are various possible reasons why retirement might affect health, there are various possible explanations for our results. We leave a full investigation of the various possible mechanisms by which retirement might affect health to future research. However, as suggested in work by Ruhm (2004), one possible source of improvements in health is that not working may promote better health-related behavior. While not shown here, we also examined age patterns of current smoking prevalence, and the frequency and amount of alcohol consumption and physical exercise. On most indicators, neither men nor women showed a significant post-retirement age change in behavior. However, men were about $5 \%$ and women $10 \%$ more likely to engage in "sports or physical activities that are moderately energetic" at least once a week. Several health benefits of regular moderate exercise have been noted in the clinical literature: reduced risk of ovarian cancer (Pan et al. 2005); breast cancer (Bardia et al. 2006); coronary heart disease (Manson et al. 2002). Thus, these behavior changes might account for some of the health improvements we observed. However, changes in mortality from circulatory causes are fairly large for men (14\% reduction in annual mortality risk between the ages of 65 and 74). A 5\% increase in regular exercise would likely result in less than a one percent reduction in mortality risk, a small part of the post-retirement mortality drop. ${ }^{3}$

The nature of our research strategy affects the interpretation of our results. We use exogenous and well known features of the retirement system in the U.K. to identify

\footnotetext{
${ }^{3}$ Since the measures collected in ELSA do not correspond to those in clinical trials it is not possible to give a full accounting of what effect a behavioral change of this magnitude might have on disease prevalence or activity limitation. But to get a rough idea, the post-retirement deviations in the probability of regular moderate exercise are on the order of $8-10 \%$ for women and $4-5 \%$ for men. One recent study (Tanasescu et al. 2002) finds an $18 \%$ reduction in risk of heart attacks in men who do DAILY brisk walking of 30 minutes. If we assume that exercising twice a week confers a $6 \%$ reduction and we assume that half of the $(5 \%)$ retirement-induced exercise increase was of the daily type and half was of the twice-per-week type, then retirement may produce a $.05 *(.5 * 18+.5 * 6)=.05 * 12=0.6 \%$ decrease in heart attack risk in men.
} 
the contemporaneous effect of retirement on health. As discussed above, it seems quite likely that the effect of retirement on health varies across the population and across circumstances leading to retirement. Our estimates should be interpreted as averages across individuals induced to retire at the normal retirement age in the U.K (Imbens and Angrist, 1994). As we have also argued, our method has some chance identifying the contemporaneous effect of retirement on health. However, to the extent that retirement expectations affect health investments, we will not pick up such shifts. We suspect such effects are small, and, as we have argued, would, if anything, tend to reinforce the positive effect of retirement on health.

It is natural to speculate about whether our estimates have implications for the advisability of changing early or normal retirement age in the U.S. Our estimates would seem to suggest that delaying retirement would tend to postpone the positive health effects of retirement. However, this does not mean that recent shifts that have been introduced to encourage the delay in retirement are a mistake. Instinctually as economists we tend to favor policies that do not distort behavior. In the context of retirement policy, this means policies that neither encourage nor discourage early retirement. Recent changes in social security rules such as the increase in the delayed retirement credit reduced the disincentives build into the program for delayed retirement. As long as individuals are aware of the health consequences of retirement, as we suspect they are, there is no reason to shy away from such policies. By the same token, our results suggest that policies based on the paternalistic notion that work is good for individuals is mistaken. 
We interpret our results as encouraging for researchers studying retirement who have made the assumption that health, or, at least, changes in health are largely exogenous to retirement behavior. Given the paucity of plausible instruments for health, this is good news, indeed. At the same time, we have found some differences between results based on self-reported measures of health and functional status, and "objective" physical measurements. Given that the self reports and physical measurements do not tap exactly the same construct, these results are, at best, suggestive. However, they are consistent with recent research that has emphasized the extent to which survey responses to health and physical capacity questions depend on social context. 


\section{References}

Bardia, Aditya, Lynn C. Hartmann, , Celine M. Vachon, , Robert A. Vierkant, , Alice H. Wang, , Janet E. Olson, , Thomas A. Sellers, James R. Cerhan. 2006.

Recreational Physical Activity and Risk of Postmenopausal Breast Cancer Based on Hormone Receptor Status. Archives of Internal Medicine 166:2478-2483.

Blundell, Richard and Paul Johnson. 1999. "Pensions and Retirement in the United Kingdom," in Social Security and Retirement Around the World, Jonathan Gruber and David Wise, editors, The University of Chicago Press, Chicago, IL.

Blundell, Richard, Costas Meghir and Sarah Smith. 2002. "Pension Incentives and the Pattern or Early Retirement,” The Economic Journal, 112:C153-C179.

Bound, John, Todd Stinebrickner and Timothy Waidmann. 2004. "Using a Structural Model to Simulate the Effect of Changes to the OASDI and Medicare Programs." Social Security Administration Annual Retirement Research Conference, Washington, 2004.

Card, David, Carlos Dobkin and Nicole Maestas .2007. “The Impact of Nearly Universal Insurance Coverage on Health Care Utilization: Evidence from Medicare," http://people.ucsc.edu/ cdobkin/Papers/Medicare.pdf.

Charles, Kerwin K. 2004. “Is Retirement Depressing?: Labor Force Inactivity and Psychological Well-Being in Later Life" in Research in Labor Economics, vol. 23, edited by S.W. Polachek.

Dave, Dhaval, Inas Rashad, and Jasmina Spasojevic, 2006, “The Effects of Retirement on Physical and Mental Health Outcomes," NBER WP 12123. 
Grossman, Michael. 1972. "On the Concept of Health Capital and the Demand for Health," Journal of Political Economy, 80:223-255.

Guralnik, J. M., Simonsick, E. M., Ferrucci, L., Glynn, R. J., Berkman, L. F., Blazer, D. G., Scherr, P. A., and Wallace, R. B. 1994. A short physical performance battery assessing lower extremity function: association with self-reported disability and prediction of mortality and nursing home admission. J Gerontol, 49(2), M85-94.

Imbens, Guido W. and Joshua D. Angrist. 1994. Identification and Estimation of Local Average Treatment Effects. Econometrica 62(2):467-475.

Manson JE, Greenland P, LaCroix AZ, et al. 2002. Walking compared with vigorous exercise for the prevention of cardiovascular events in women. New England Journal of Medicine 347:716-725.

National Heart Lung and Blood Institute. 2007. Metabolic Syndrome. http://www.nhlbi.nih.gov/health/dci/Diseases/ms/ms_whatis.html, accessed $7 / 21 / 2007$.

Lawlor, D.A., Ebrahim, S. and Smith, G.D. 2002. Role of endogenous oestrogen in aetiology of coronary heart disease: analysis of age related trends in coronary heart disease and breast cancer in England and Wales and Japan. BMJ 325(7359): $311-312$

Pan, San Yi Anne-Marie Ugnat, Yang Mao, and The Canadian Cancer Registries Epidemiology Research Group. 2005. "Physical Activity and the Risk of Ovarian Cancer: A Case-Control Study in Canada," International Journal of Cancer 117(2):300-307. 
Ruhm, Christopher. 2004. "Macroeconomic Conditions, Health and Mortality" Forthcoming in Elgar Companion to Health Economics, edited by Andrew M. Jones, Cheltenham, UK: Edward Elgar Publishing.

Tanasescu, Mihaela, Michael F. Leitzmann, Eric B. Rimm, Walter C. Willett, Meir J. Stampfer, Frank B. Hu. 2002. Exercise Type and Intensity in Relation to Coronary Heart Disease in Men JAMA.288:1994-2000. 


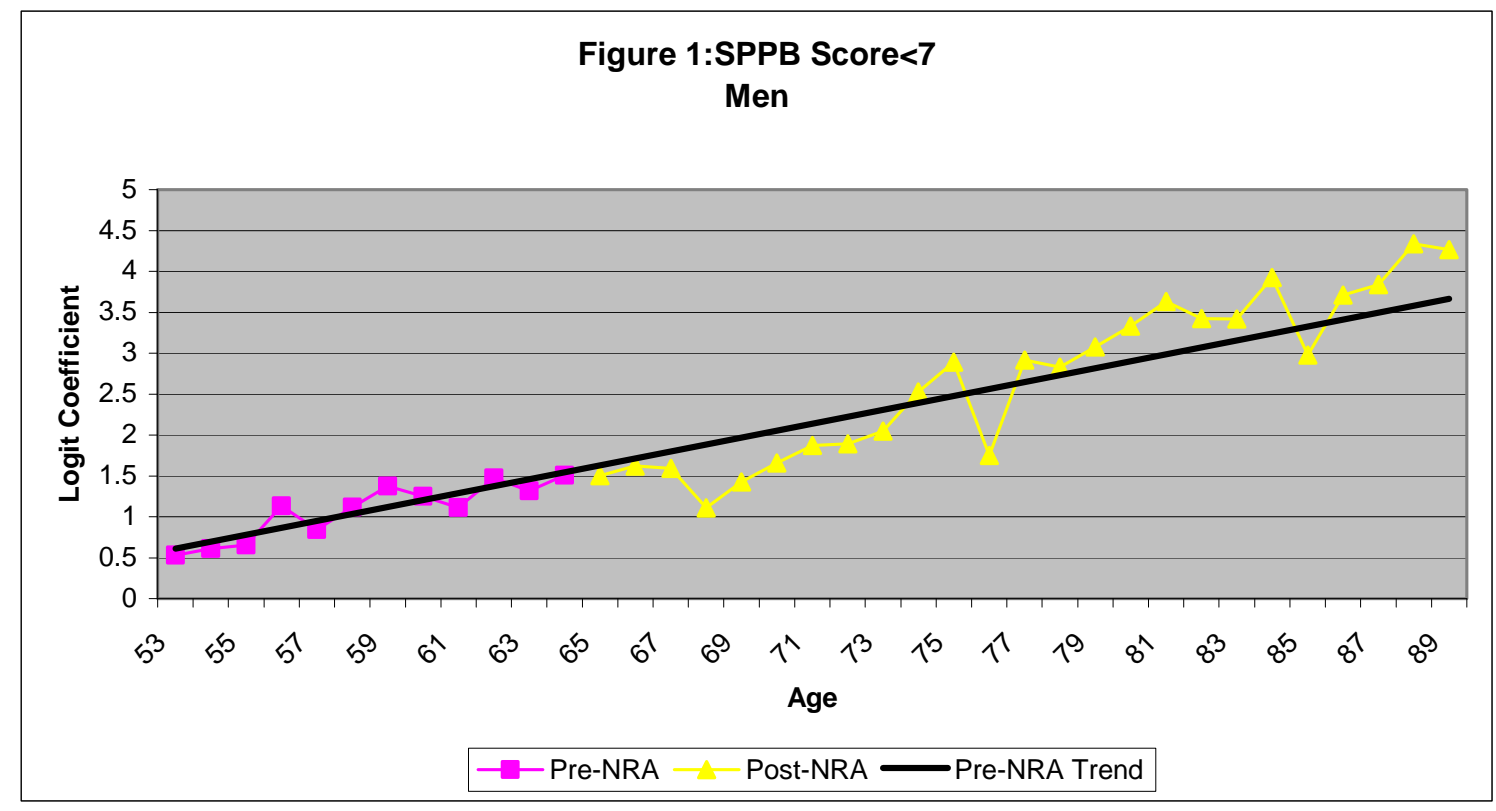

Weighted Sum of Post-NRA coeffs

All Post-NRA First 10 years

Test of Post-NRA coeffs $=0$ (z)

$-12.456$

$-19.385$

P-value

$-1.246$

$-2.394$

Source: English Longitudinal Study of Aging, Wave 2(2004/2005)

$0.213 \quad 0.017$

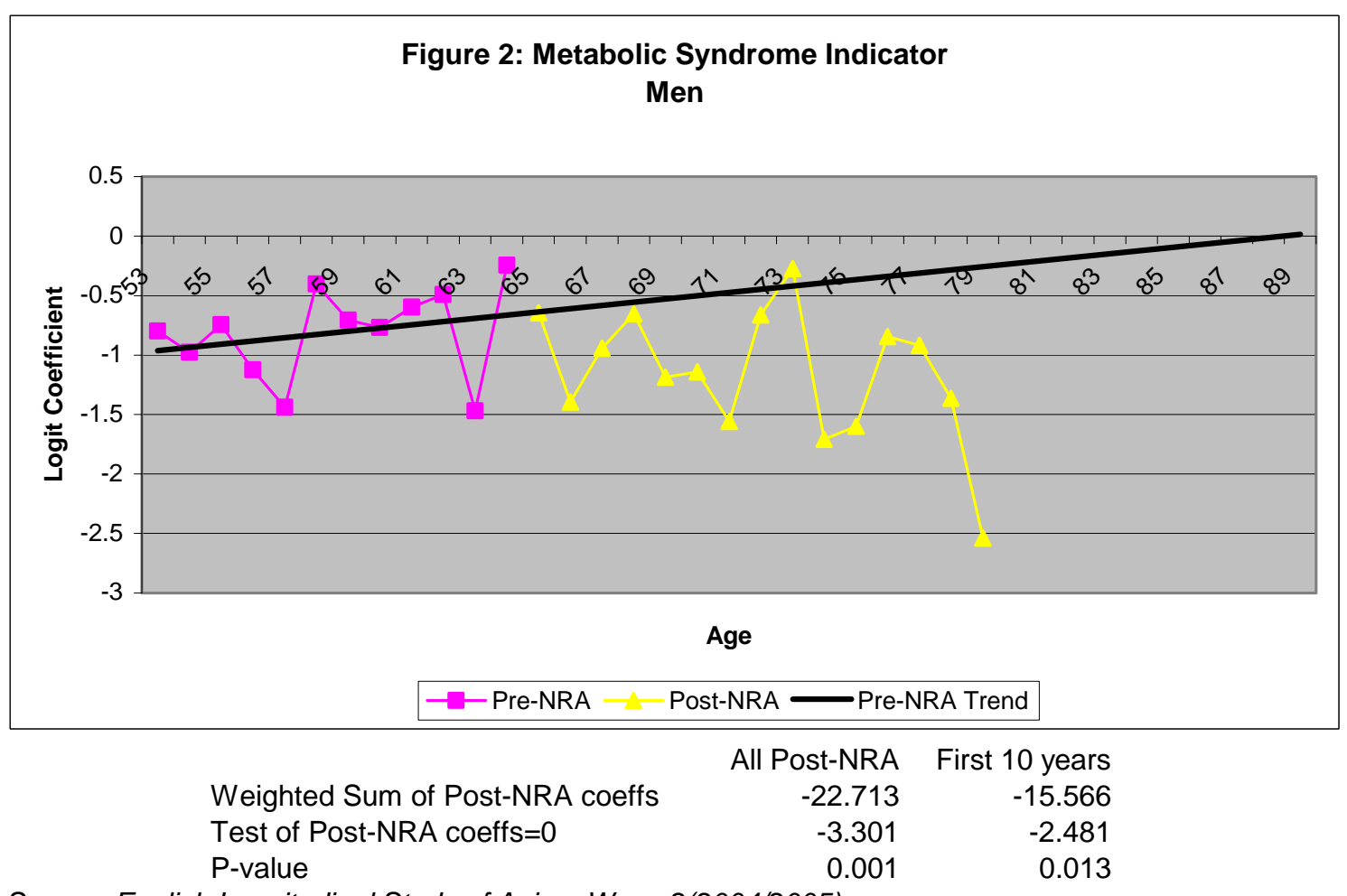

Source: English Longitudinal Study of Aging, Wave 2(2004/2005) 


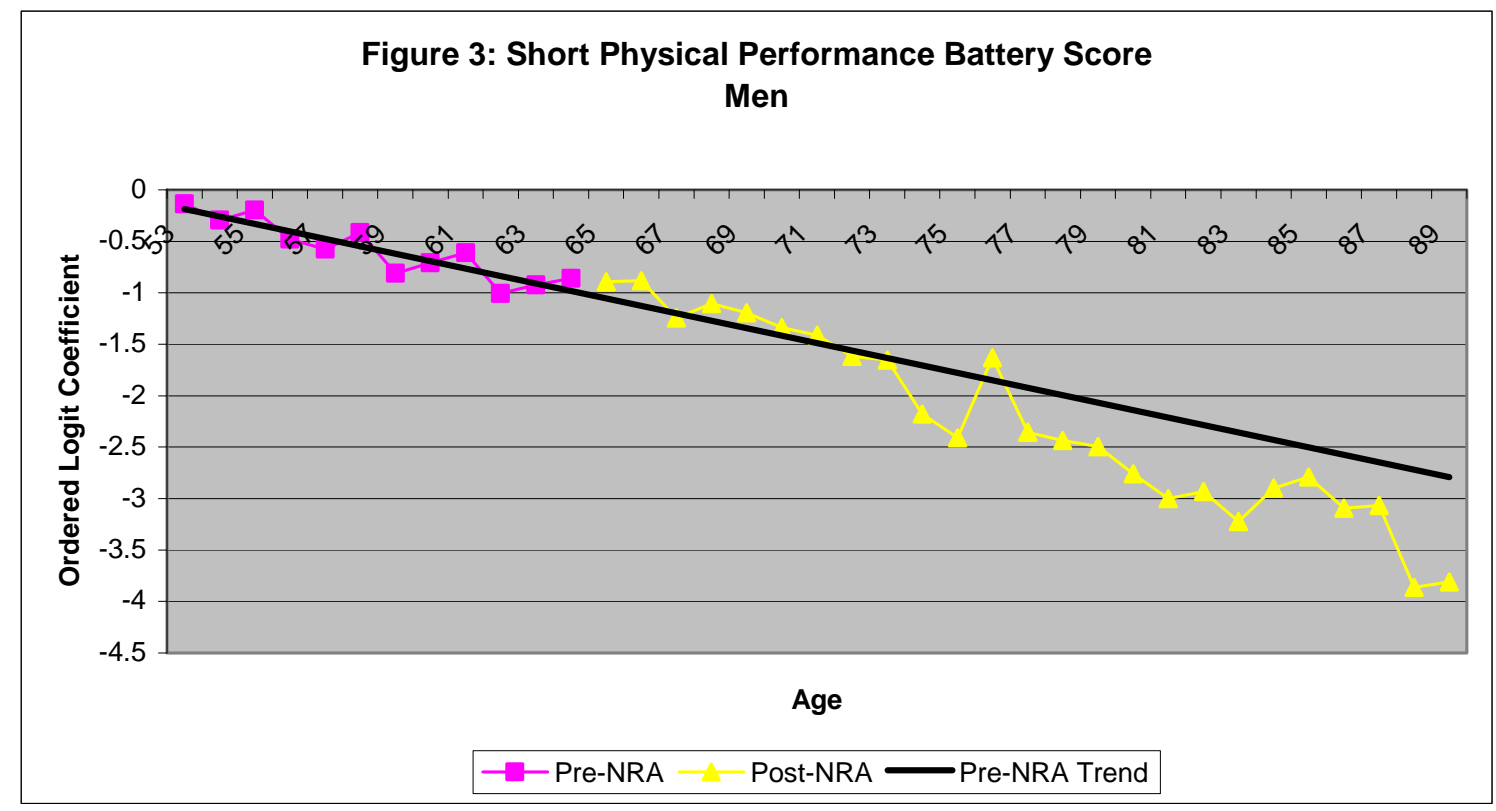

Weighted Sum of Post-NRA coeffs

All Post-NRA First 10 years

Test of Post-NRA coeffs $=0$

$-23.230 \quad 11.293$

P-value

$-1.548$

0.922

Source: English Longitudinal Study of Aging, Wave 2(2004/2005)

$0.122 \quad 0.356$

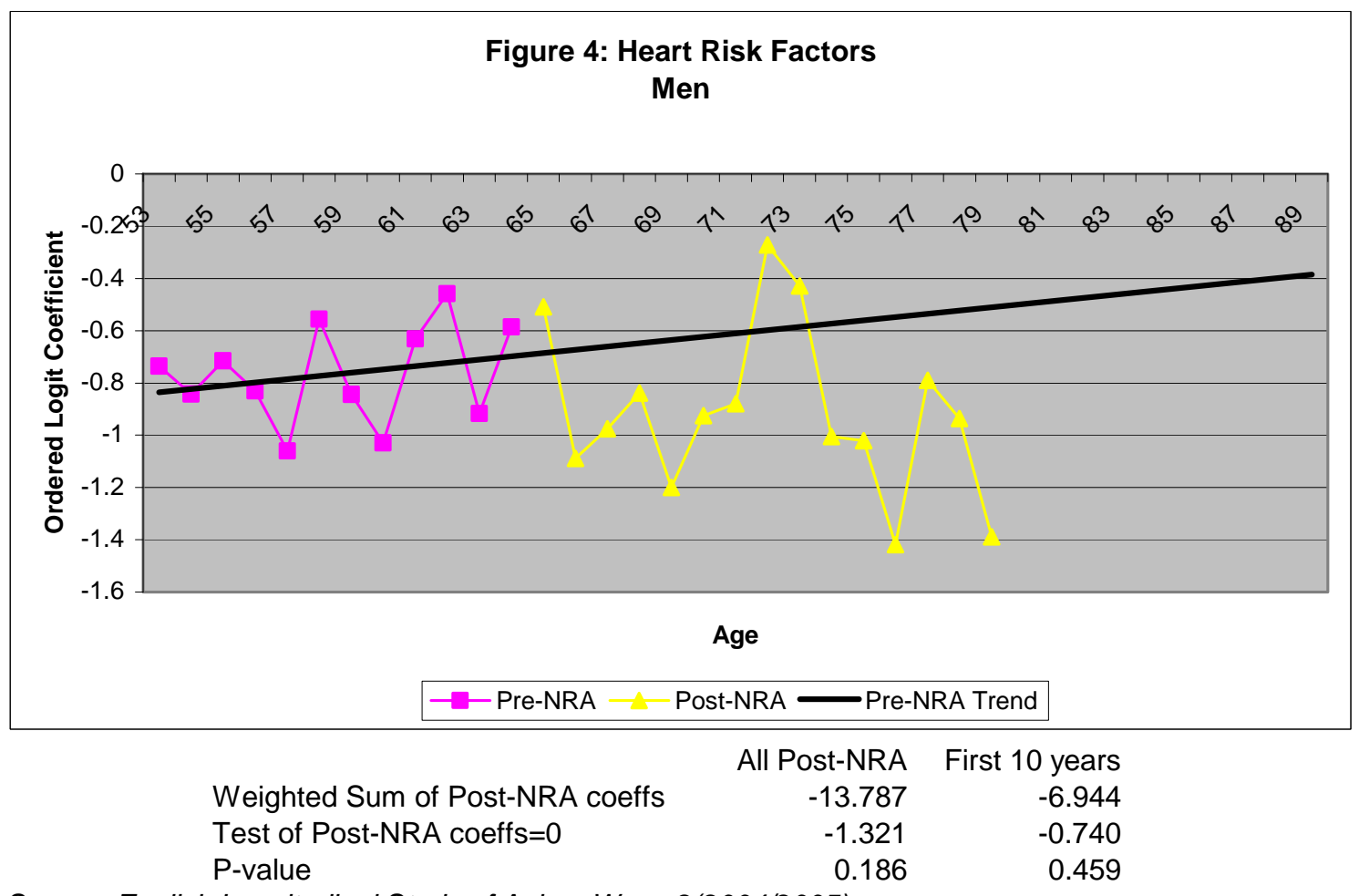

Source: English Longitudinal Study of Aging, Wave 2(2004/2005) 


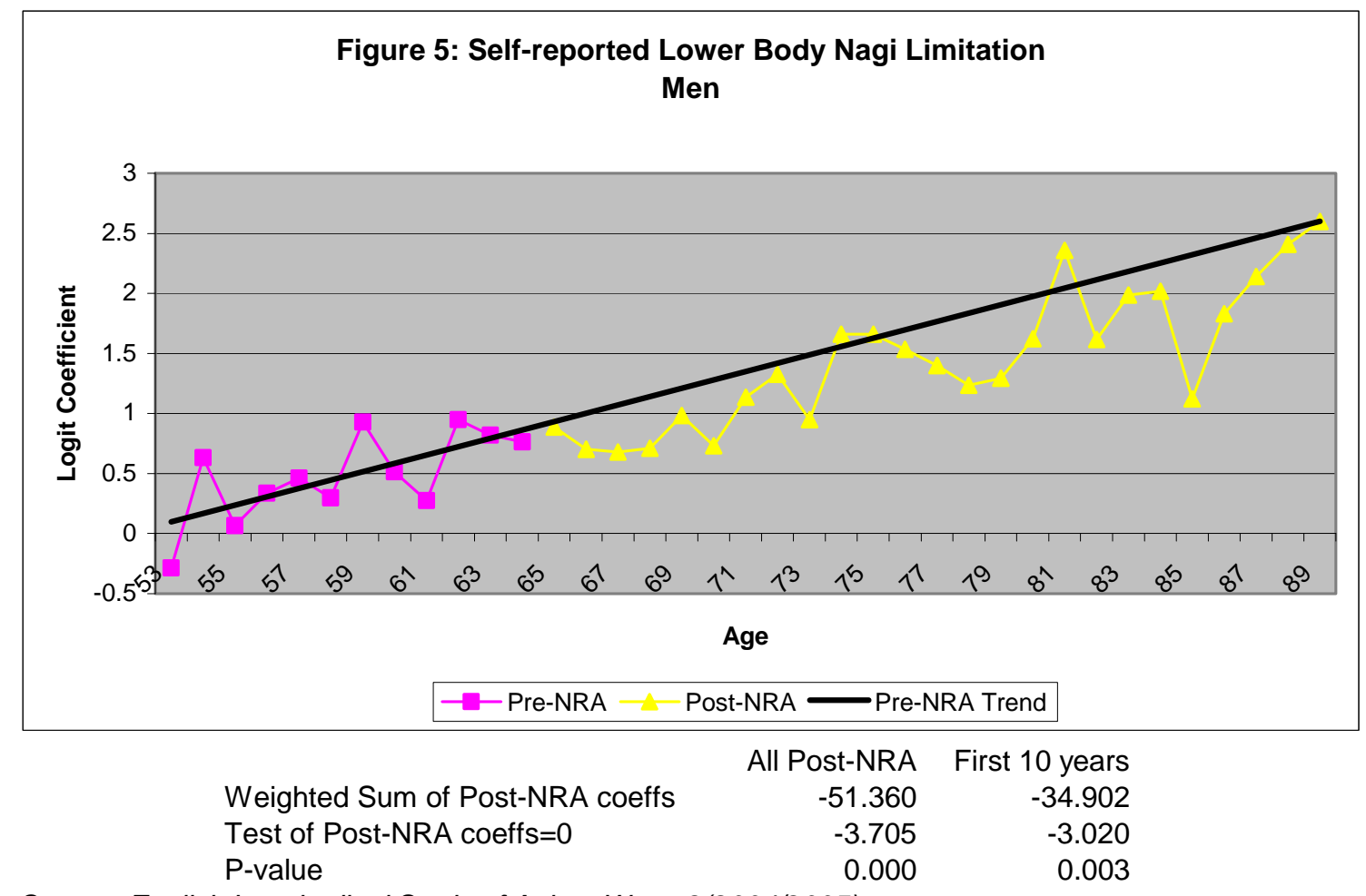

Source: English Longitudinal Study of Aging, Wave 2(2004/2005)



Weighted Sum of Post-NRA coeffs

All Post-NRA First 10 years

0.765

0.779

$P$-value

$0.444 \quad 0.436$

Source: English Longitudinal Study of Aging, Wave 2(2004/2005) 




Weighted Sum of Post-NRA coeffs

All Post-NRA First 10 years

Test of Post-NRA coeffs $=0$

$-136.400 \quad-68.245$

P-value

$-8.643 \quad-5.269$

Source: English Longitudinal Study of Aging, Wave 2(2004/2005)

$0.000 \quad 0.000$



Weighted Sum of Post-NRA coeffs

All Post-NRA First 10 years

Test of Post-NRA coeffs $=0$

$-55.484$

$-27.258$

P-value

$-3.790$

$-2.291$

$0.000 \quad 0.022$

Source: English Longitudinal Study of Aging, Wave 2(2004/2005) 




Source: English Longitudinal Study of Aging, Wave 2(2004/2005) 




Weighted Sum of Post-NRA coeffs

All Post-NRA First 10 years

Test of Post-NRA coeffs $=0$

$-14.420 \quad-9.331$

P-value

$-1.691$

$-1.275$

Source: English Longitudinal Study of Aging, Wave 2(2004/2005)

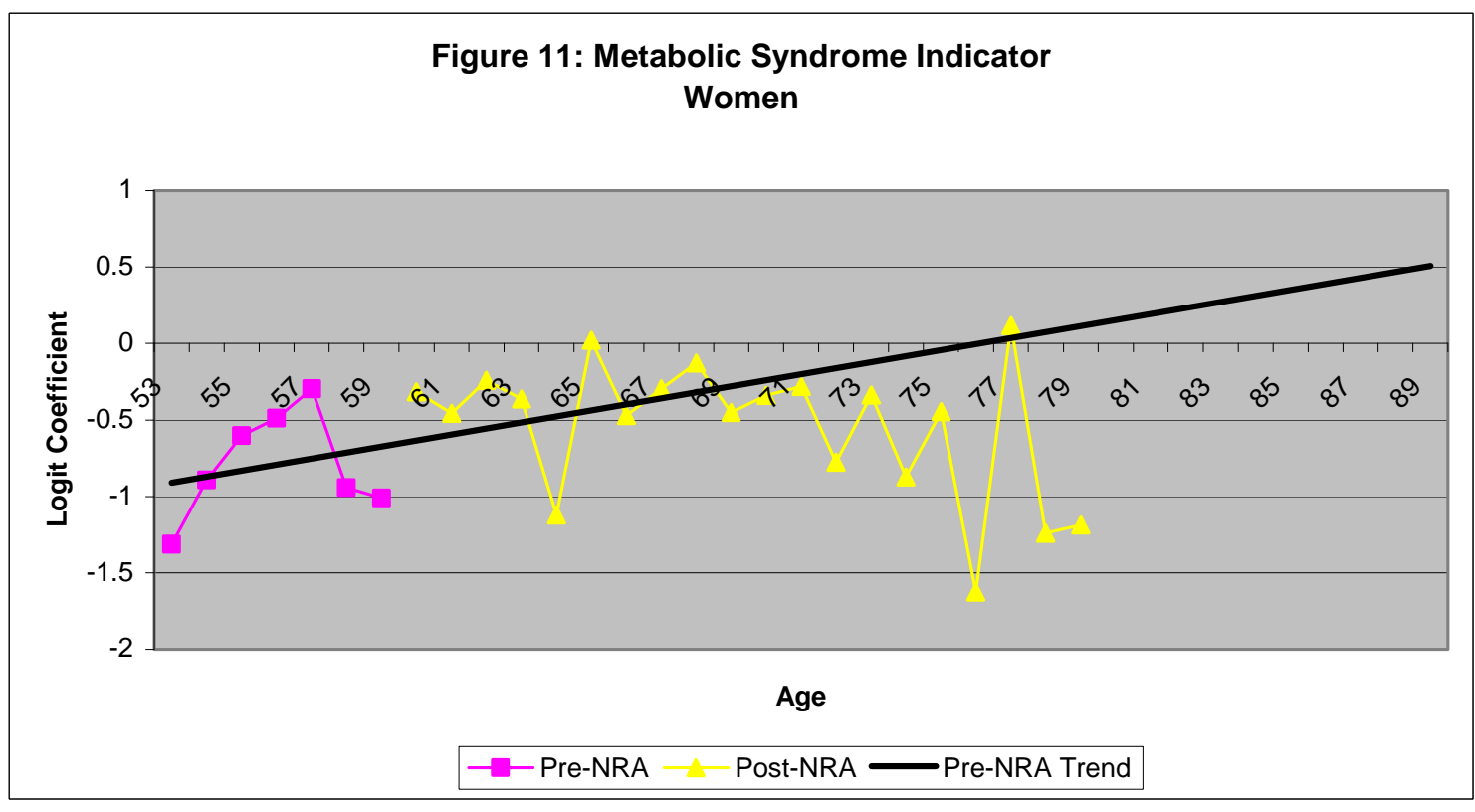

Weighted Sum of Post-NRA coeffs

All Post-NRA First 10 years

Test of Post-NRA coeffs $=0$

7.204

7.589

P-value

1.202

1.409

$0.229 \quad 0.159$

Source: English Longitudinal Study of Aging, Wave 2(2004/2005) 


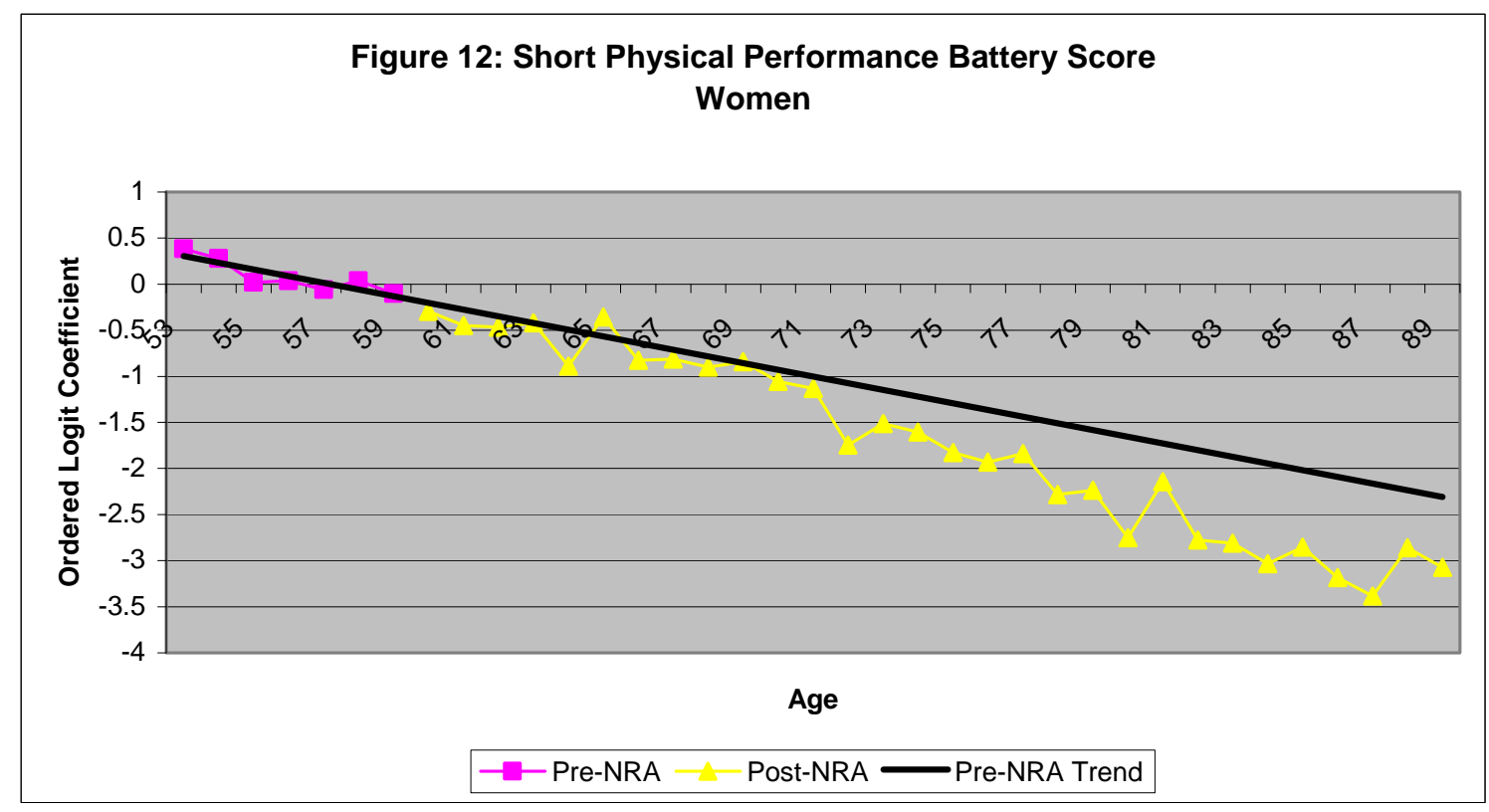

Weighted Sum of Post-NRA coeffs

All Post-NRA First 10 years

Test of Post-NRA coeffs $=0$

$-54.087$

$-18.990$

$P$-value

$-4.091$

$-1.689$

0.091

Source: English Longitudinal Study of Aging, Wave 2(2004/2005)



Weighted Sum of Post-NRA coeffs

All Post-NRA First 10 years

Test of Post-NRA coeffs $=0$

7.448

3.707

$P$-value

0.741

0.418

Source: English Longitudinal Study of Aging, Wave 2(2004/2005) 


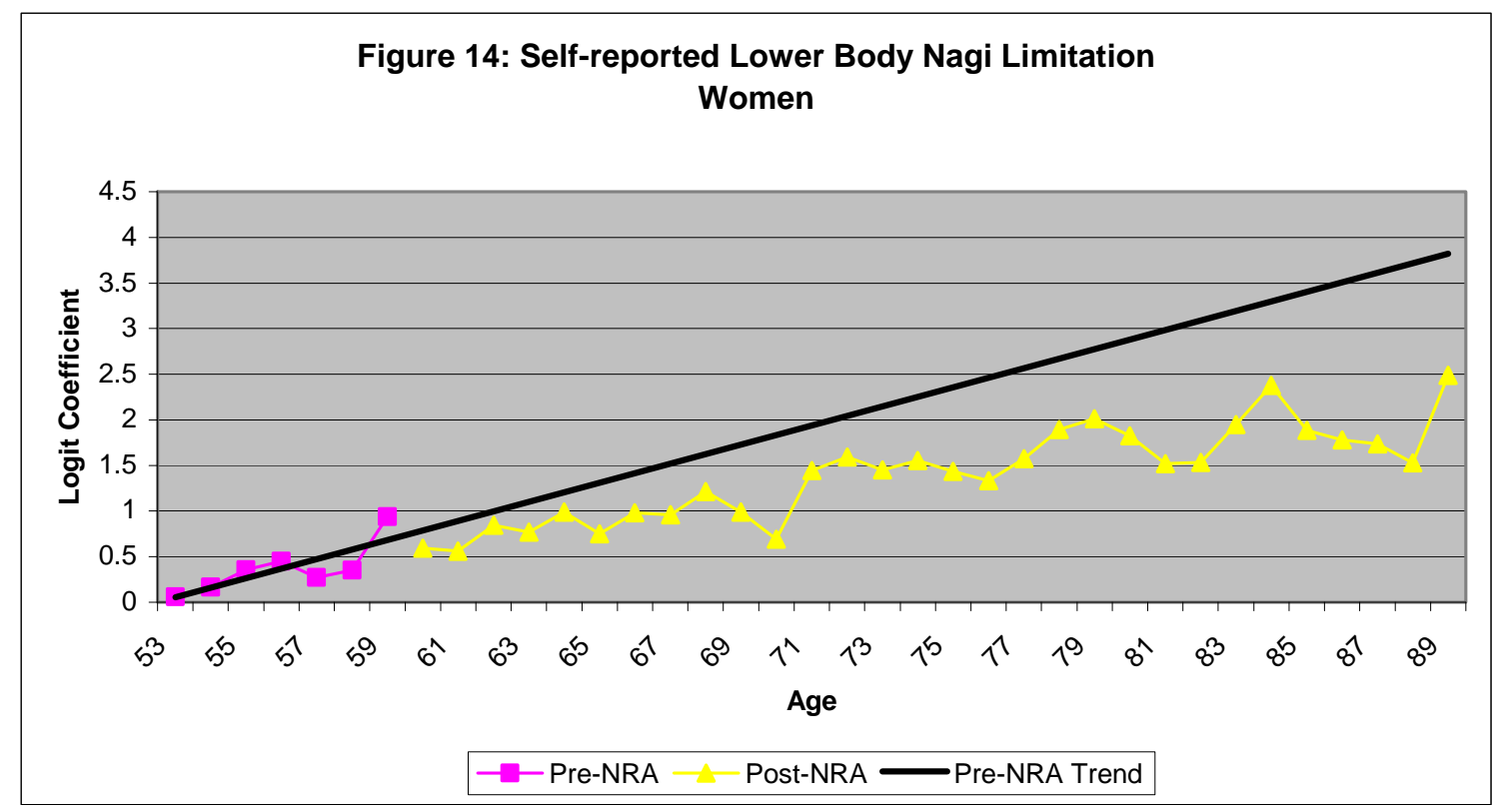

Weighted Sum of Post-NRA coeffs

All Post-NRA First 10 years

Test of Post-NRA coeffs $=0$

$-58.331$

$-27.981$

$P$-value

$-4.702$

$-2.627$

Source: English Longitudinal Study of Aging, Wave 2(2004/2005)

0.009

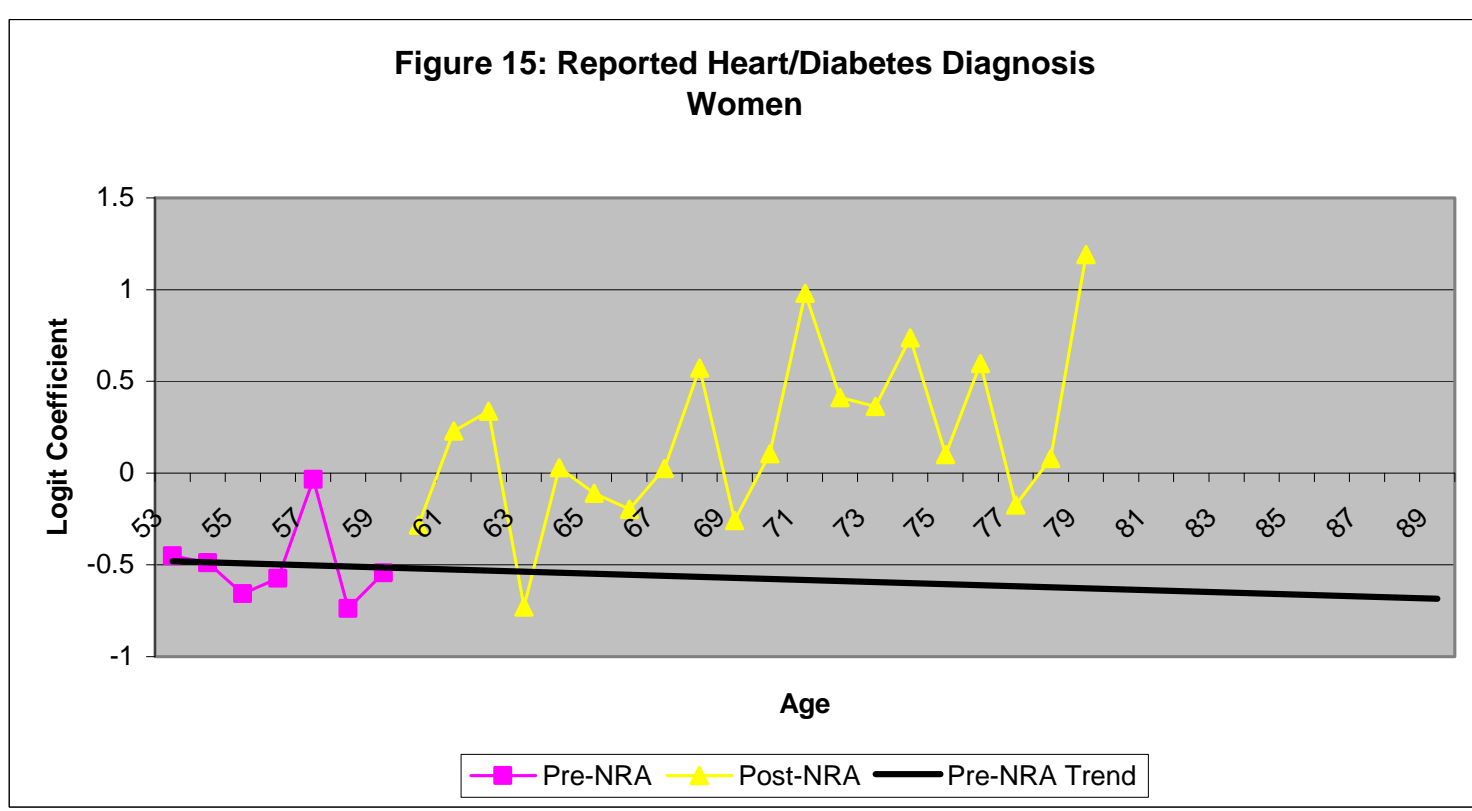

Weighted Sum of Post-NRA coeffs

All Post-NRA First 10 years

Test of Post-NRA coeffs $=0$

$\begin{array}{rr}25.513 & 16.492 \\ 4.050 & 2.923 \\ 0.000 & 0.003\end{array}$

Source: English Longitudinal Study of Aging, Wave 2(2004/2005) 




Weighted Sum of Post-NRA coeffs

All Post-NRA First 10 years

Test of Post-NRA coeffs $=0$

$-74.287$

$-29.932$

$P$-value

$-5.038$

$-2.440$

Source: English Longitudinal Study of Aging, Wave 2(2004/2005)

0.015

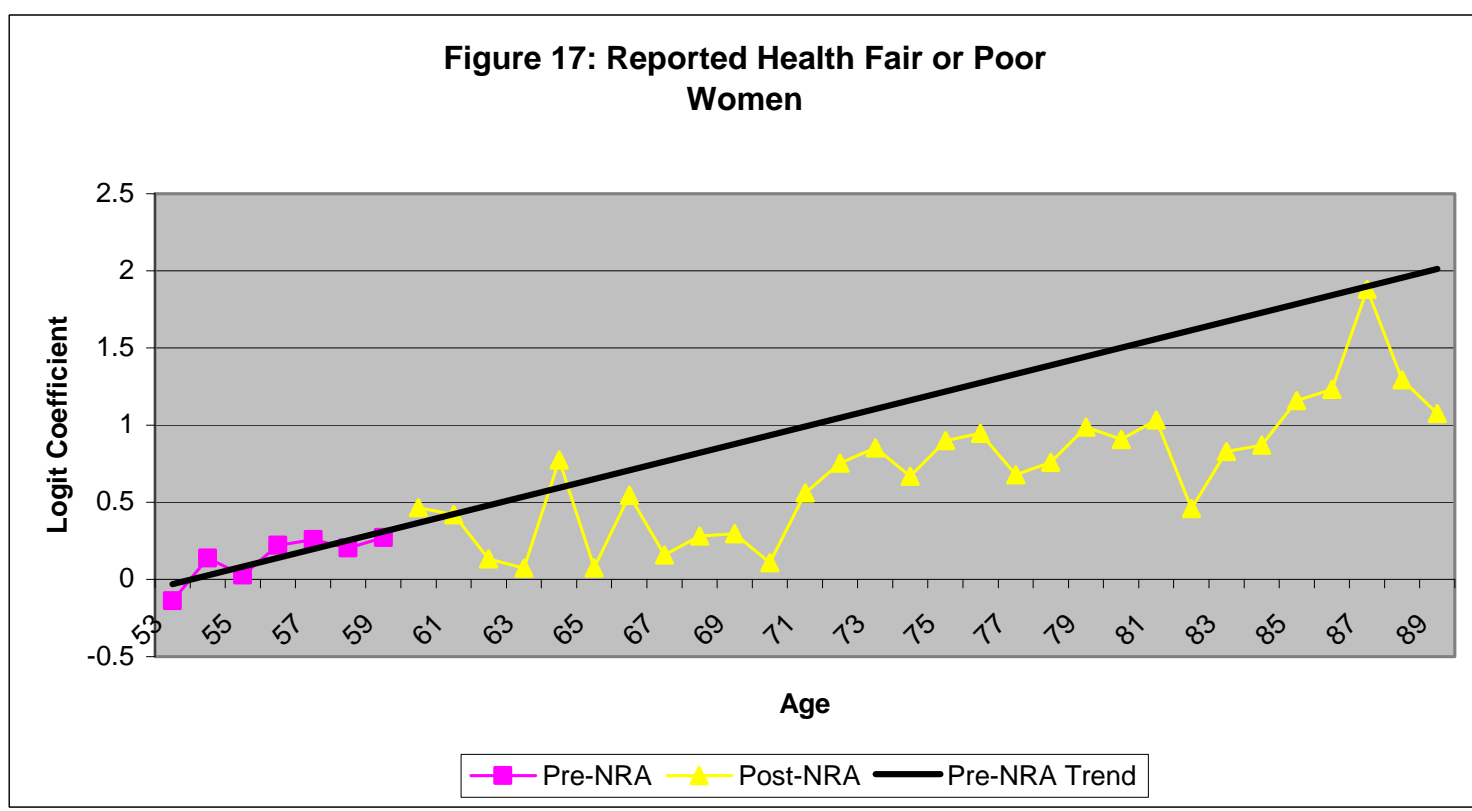

Weighted Sum of Post-NRA coeffs

All Post-NRA First 10 years

Test of Post-NRA coeffs $=0$

$-78.273$

$-43.263$

$P$-value

$-6.126$

$-4.083$

Source: English Longitudinal Study of Aging, Wave 2(2004/2005) 




Weighted Sum of Post-NRA coeffs

All Post-NRA First 10 years

Test of Post-NRA coeffs $=0$

$-167.015$

$-72.755$

P-value

$-11.463$

$-6.017$

Source: English Longitudinal Study of Aging, Wave 2(2004/2005)

0.000 
Figure 19: Internal Cause Mortality, Males, England and Wales 2005



- Cause-specific log mortality rate

Predicted In(Mortality)

Source: Authors' analysis of vital statistics data from UK Office of National Statistics.

Figure 20: Internal Cause Mortality, Females, England and Wales 2005

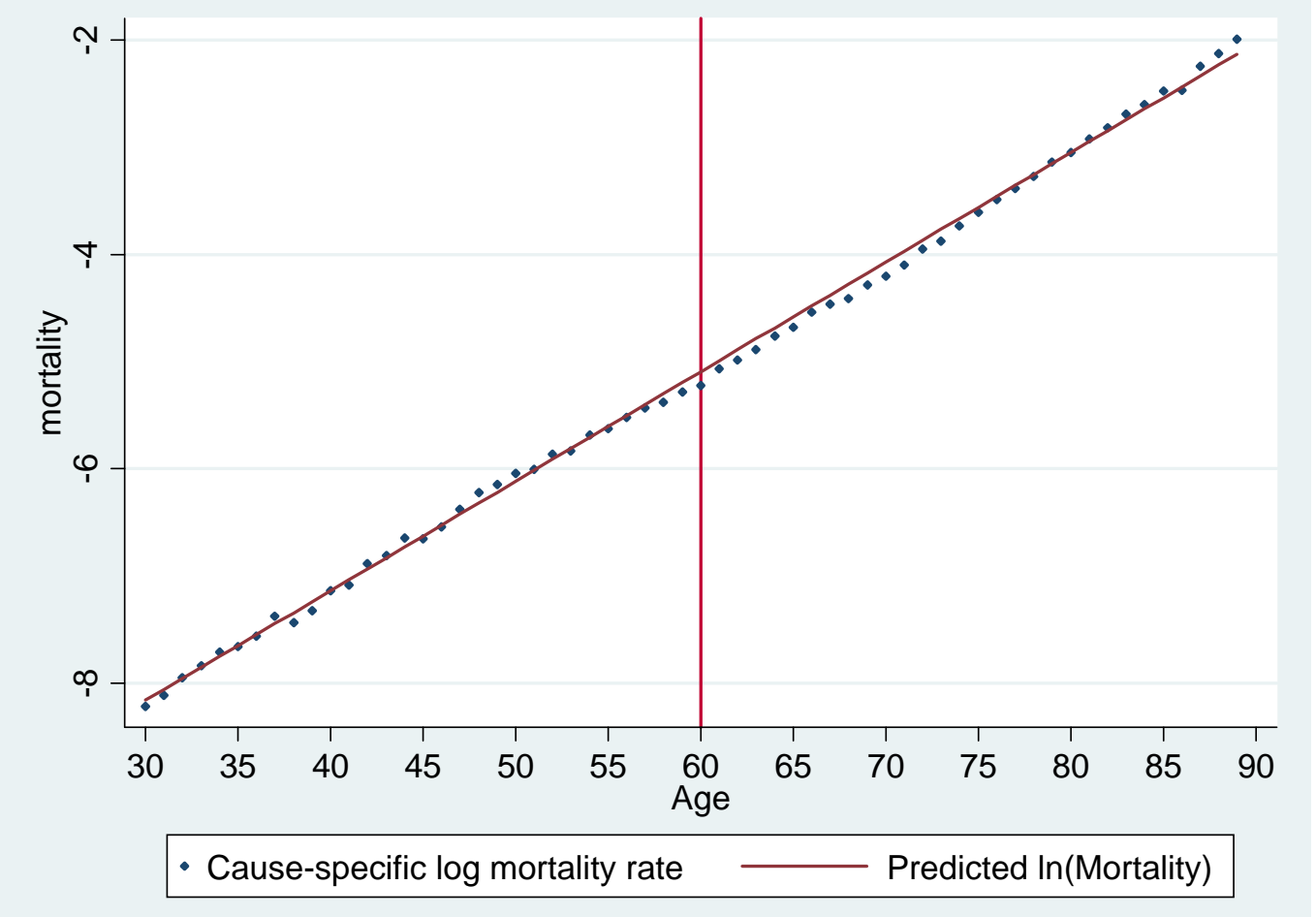

Source: Authors' analysis of vital statistics data from UK Office of National Statistics. 
Figure 21: Cancer Mortality, Males, England and Wales 2005

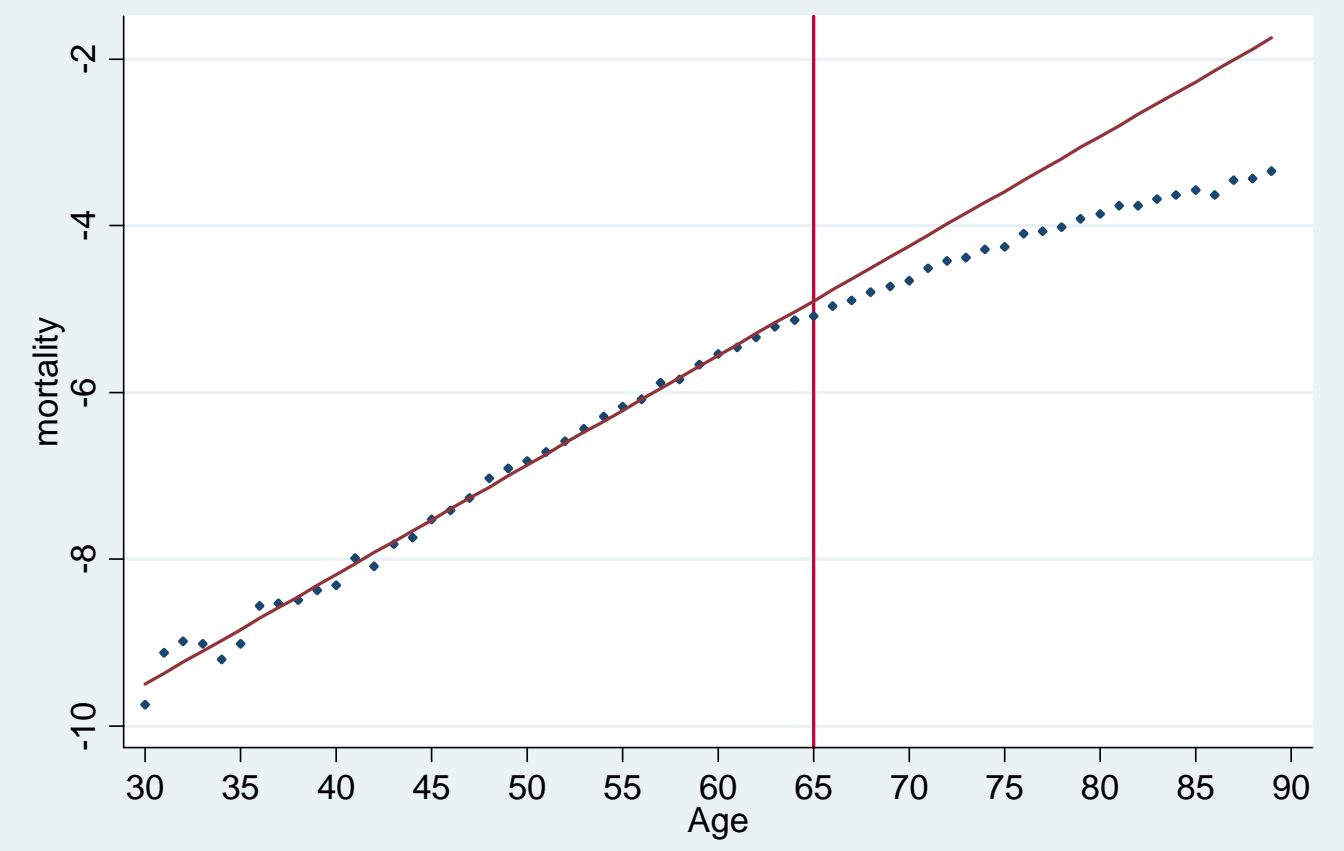

- Cause-specific log mortality rate ㄴ Predicted In(Mortality)

Source: Authors' analysis of vital statistics data from UK Office of National Statistics.

Figure 22: Cancer Mortality, Females, England and Wales 2005

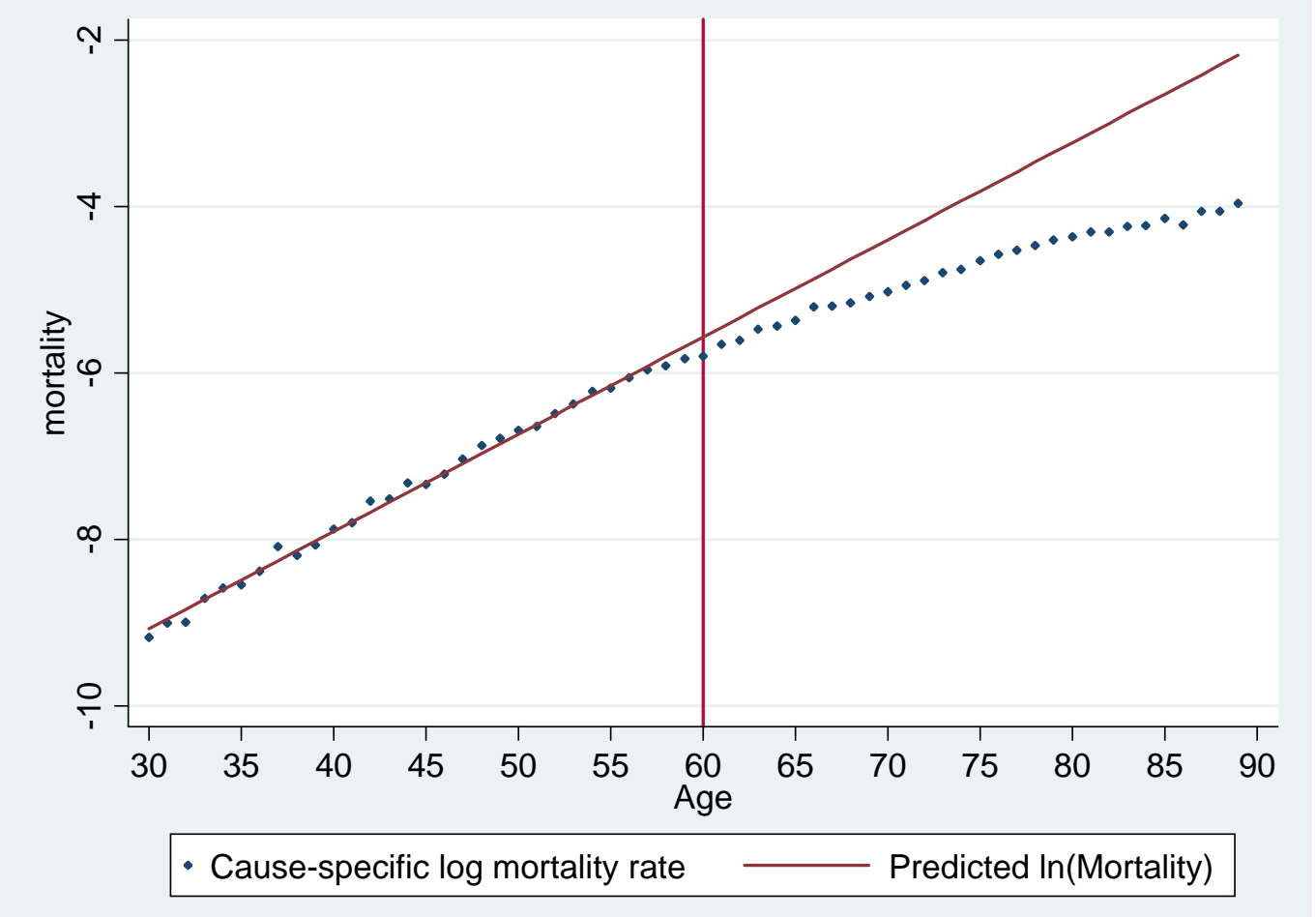

Source: Authors' analysis of vital statistics data from UK Office of National Statistics. 
Figure 23: Nervous System Mortality, Males, England and Wales 2005



- Cause-specific log mortality rate $\longrightarrow$ Predicted $\ln ($ Mortality)

Source: Authors' analysis of vital statistics data from UK Office of National Statistics.

Figure 24: Nervous System Mortality, Females, England and Wales 2005

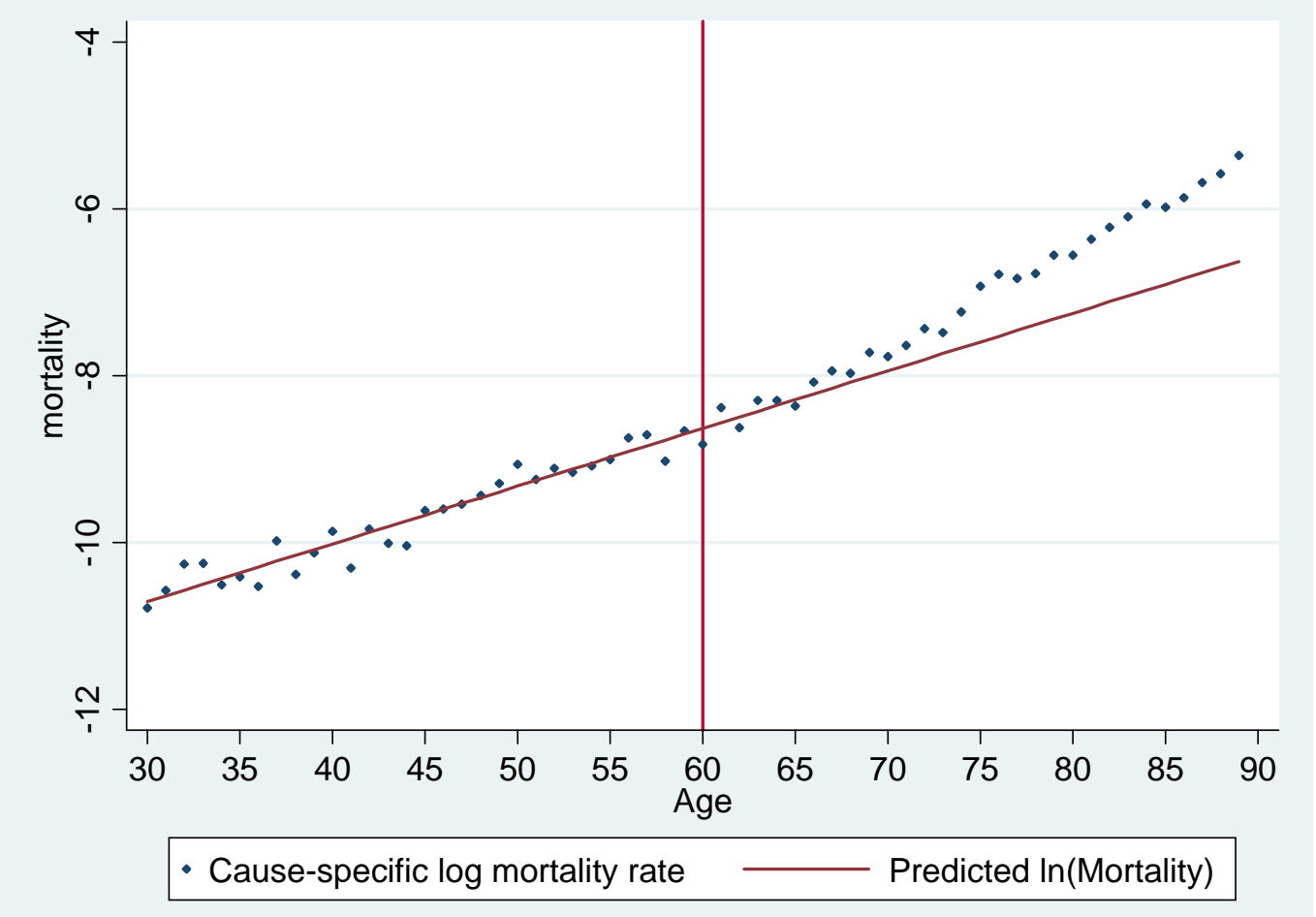

Source: Authors' analysis of vital statistics data from UK Office of National Statistics. 
Figure 25: Circulatory System Mortality, Males, England and Wales 2005

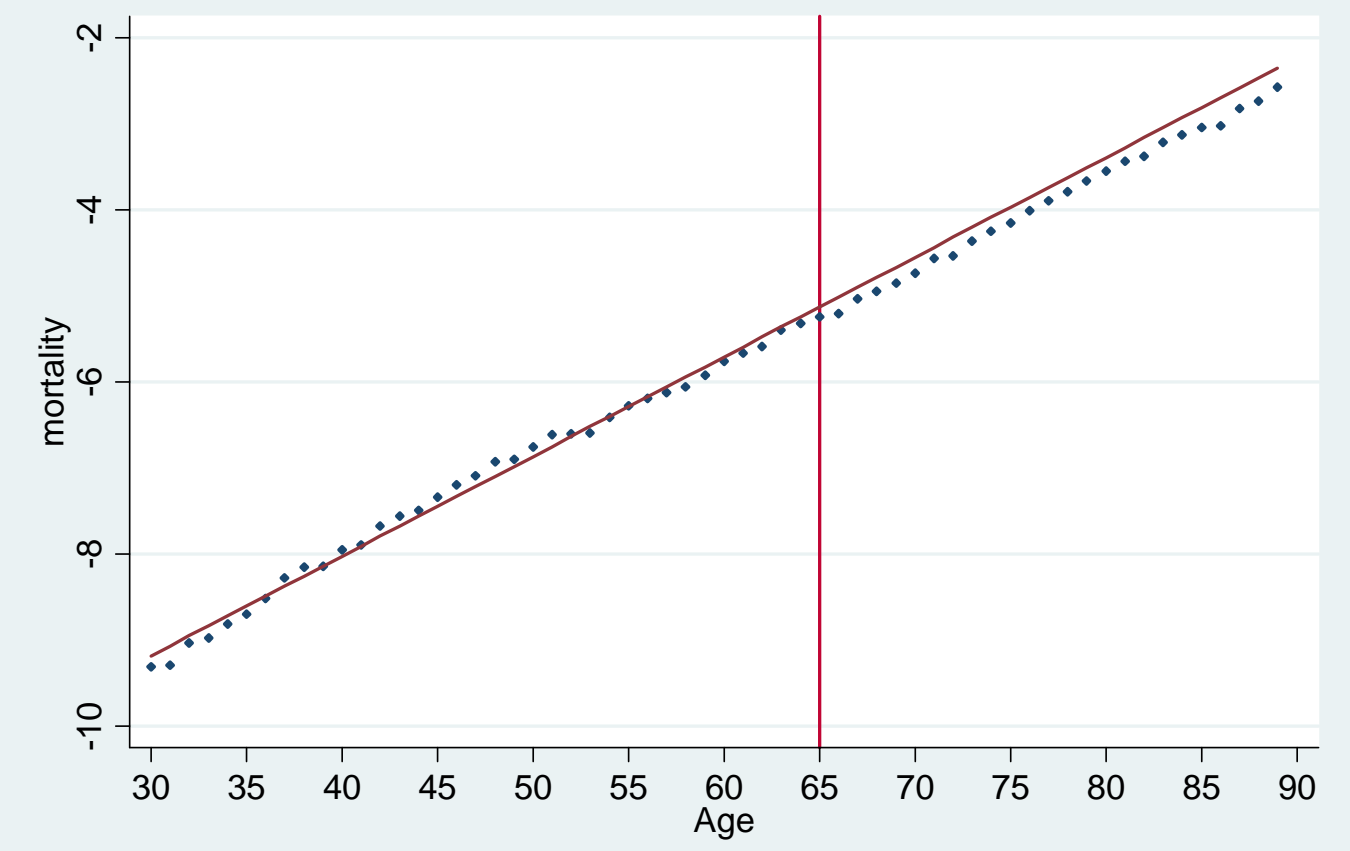

- Cause-specific log mortality rate _ Predicted In(Mortality)

Source: Authors' analysis of vital statistics data from UK Office of National Statistics.

Figure 26: Circulatory System Mortality, Females, England and Wales 2005



Source: Authors' analysis of vital statistics data from UK Office of National Statistics. 
Figure 27: External Cause Mortality, Males, England and Wales 2005



- Cause-specific log mortality rate Predicted In(Mortality)

Source: Authors' analysis of vital statistics data from UK Office of National Statistics.

Figure 28: External Cause Mortality, Females, England and Wales 2005

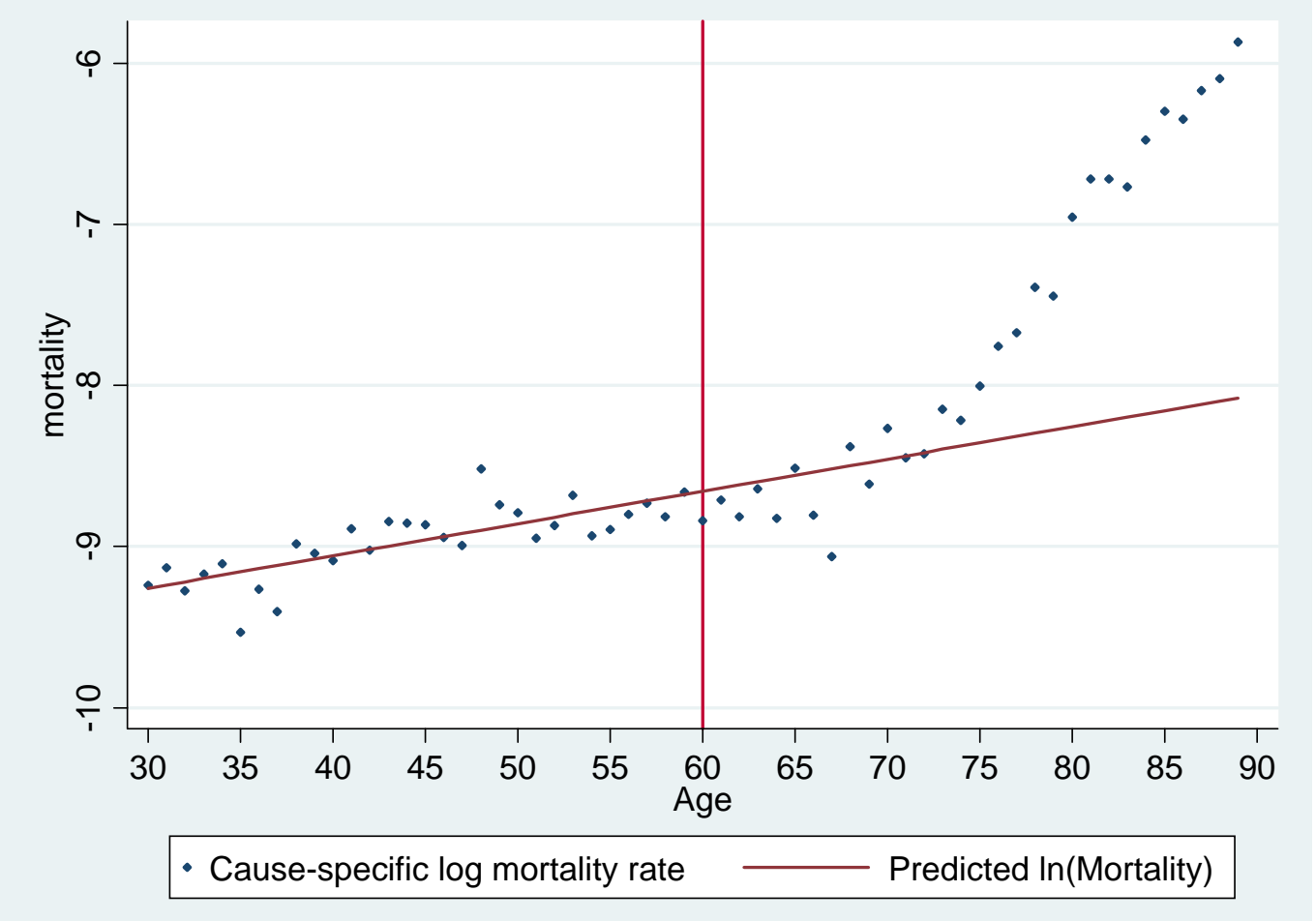

Source: Authors' analysis of vital statistics data from UK Office of National Statistics. 